\title{
El Storyworld en la narrativa de los Juegos Documentales Interactivos: el caso de Fort McMoney
} The storyworld in the storytelling of the Interactive Documentary Games: the case of Fort McMoney

Mar Marcos Molano

Profesora Titular

(Universidad Complutense de Madrid)

España

https://orcid.org/0000-0002-8738-9244

Sergio Fabián Romero Chamorro

Docente Investigador

(Universidad Nacional Tres de Febrero)

Argentina

https://orcid.org/0000-0002-2671-1420

Michael Santorum González

Doctor en Ciencias de la Información

(Universidad Complutense de Madrid)

España

http://orcid.org/0000-0002-2330-7756

Fecha de recepción: 14 de septiembre de 2018

Fecha de revisión: 3 de diciembre de 2018

Fecha de publicación: 1 de enero de 2019

Para citar este artículo: Marcos Molano, M., Romero Chamorro, S.F. y Santorum González, M. (2019). El Storyworld en la narrativa de los Juegos Documentales Interactivos: el caso de Fort McMoney, Icono 14, 17 (1), 39-59. doi: 10.7195/ri14.v17i1.1246 
40| Mar Marcos Molano, Sergio Fabián Romero Chamorro y Michael Santorum González MONOGRÁFICO

\section{Resumen}

Storyworld, mundo o universo narrativo, es un concepto que, si bien puede rastrearse en el desarrollo de estudios narratológicos estructuralistas y postestructuralistas, se despliega plenamente y adquiere su especificidad con el advenimiento de la narrativa transmedia. El desarrollo de modelos que conciben el espacio como lugar cardinal donde establecer relaciones esenciales entre elementos narrativos, se relaciona con los cambios operados en el rol del espectador, que deviene usuariojugador, gracias al desarrollo de narrativas laberinticas. Revalorizar los "trayectos" narrativos posibilitando al usuario el acceso a ese mundo, realizar recorridos uni o multiplataforma o transitar las tramas, resultan fundamentales para entender en toda su magnitud los fenómenos de expansión narrativa y de storyworld. En este contexto situamos el juego documental "Fort McMoney" donde la exploración flexible del conjunto de segmentos documentales que lo componen, lo acerca a una narración emergente y caleidoscópica embriagada de mímesis, provocando en el espectador la fascinación ante la sensación de la exploración infinita de un mundo real.

Palabras clave: Universo narrativo; Interactividad; I-Docs; Webdocs; Narrativas laberínticas; Narrativas ergódicas

\section{Abstract}

Storyworld, world or narrative universe, is a concept that, although it can be tracked in the development of structuralist and poststructuralist narratological studies, unfolds completely and acquires its specificity with the advent of transmedia storytelling. The development of models which conceive the space as the main place to establish essential relationships between narrative elements is related to the changes occuring in the role of the spectator, who becomes a user-player due to the development of entangled narratives. Revalue narrative "paths" allowing the user access to that world, perform uni or multiplatform routes and move throughout the plots are fundamental to understand in all its magnitude the phenomenons of narrative expansion and storyworld. In this context we situate the documentary game "Fort McMoney" where the flexible exploration of the set of documentary segments that compose it, brings it closer to an emergent and kaleidoscopic narration 
intoxicated with mimesis, inducing in the spectator the fascination facing the feeling of the infinite exploration of a real world.

Key Words: Narrative universe; Interactivit; I-Docs; Webdocs; Labyrinthine narratives; Ergodic narratives

\section{Introducción}

La noción de storyworld ha emergido con fuerza en los últimos años y ha sido adoptada en el ámbito de la producción de contenidos de la mano de franquicias desarrolladas a partir de productos audiovisuales, sagas fantásticas literarias, cómics o videojuegos. Pero también el mundo académico ha comenzado a ocuparse de los universos narrativos como uno de los aspectos centrales de la transmedialidad desde diferentes perspectivas narratológicas, semióticas, de estudios de medios o de estudios culturales:

In recent years, we have seen a growing body of scholarship on transmediality from different perspectives: storytelling, world building, industry practices, and studies that look at both "old" media formats, such as film and television and "new" media formats such as websites, digital games, and mobile phones (...). This development indicates that the study of cross- or transmediality might slowly be maturing into a field of study in its own right (Tosca \& Klastrup en Ryan \& Thon, 2014: 295)

A su vez, teniendo en cuenta la frecuencia y forma de sus usos por las distintas comunidades mencionadas, la noción de storyworld aporta significaciones y atribuciones descriptivas, prescriptivas y operativas que demuestran su complejidad, que demandan un abordaje desde múltiples perspectivas y ameritan ubicarlo en el centro de la convergencia de medios.

El aumento de sagas cinematográficas y la irrupción posterior de series de televisión de impacto global, ha hecho que el storyworld sea tomado también por distintas comunidades de usuarios, generándose una gama de fenómenos basados 
42| Mar Marcos Molano, Sergio Fabián Romero Chamorro y Michael Santorum González MONOGRÁFICO

en el análisis especulativo y en su expansión. En el primer caso, la generación de hipótesis sobre los desarrollos próximos de las tramas, el destino de tal o cual personaje, o la importancia de un evento determinado, es llevada a cabo con una frecuencia casi diaria por youtubers. Es común que dichos narradores tengan un conocimiento claro y un "mapeo" de las líneas de parentesco entre personajes, o dispongan la presentación de datos o eventos restituyendo su unidad espaciotemporal, cuando la articulación de la serie los diseminó a lo largo de una o varias temporadas. De este modo, reconstruir tramas, revisar parentescos, ordenar temporal y espacialmente eventos que han sido presentados en paralelo, o mediante relatos no lineales, permiten a estos comentadores revisar profundamente lo ocurrido y anunciar posibles desenlaces futuros. En el segundo caso, el fenómeno es la expansión del storyworld agregándole elementos que permiten recorrer tramas alternativas, explicitando rasgos de personajes, apenas esbozados en el universo original, o directamente producto de la imaginación de los más entusiastas. Estos desarrollos se plasman en la llamada fanfiction y abarcan todo tipo de productos, desde simples escritos y dibujos, hasta complejas producciones audiovisuales. Estas ampliaciones del storyworld a veces se realizan continuando el tono de la historia, y otras, al incluir aspectos no desarrollados, "alteran las claves de interpretación de “determinadas tramas ironizándolas o incluso subvirtiéndolas" (Žižek, 1999:164).

Esta posibilidad de alteración, expansión o actualización del universo narrativo, se maximiza si se añade a la narrativa la posibilidad de la interactividad, como ocurre en los videojuegos, dado que el jugador se convierte en actor y la experiencia deviene inmersiva gracias a la ilusión de tener el control. Dicha actuación en el storyworld permite que al jugador se le otorgue una manera de articular un papel esencial en lo que ocurre en éste $y$, a diferencia de los relatos clásicos, se le proporcionan también las herramientas para controlar lo que tendrá lugar en el espacio y tiempo representados. Siempre teniendo en cuenta que la actuación no es una capacidad ilimitada para el jugador y que el propio mecanismo del videojuego revela de este modo sus propios límites y su carácter preprogramado.

En este punto es posible aventurar que si el videojuego construyera narraciones más elaboradas superaría su reduccionismo basado en la destreza del jugador y podría plantearle retos de otras características más cognoscitivas que instrumentales. 
Es precisamente en este escenario donde los Juegos Documentales Interactivos se erigen en esa posibilidad más cognoscitiva que instrumental, revitalizando la narración del videojuego, al ofrecer una participación lúdica profundamente reflexiva que habilita al jugador a la toma de decisiones que afectan tanto al mundo creado como a la narración desarrollada. El diseño de este tipo de experiencias es imposible sin una construcción profunda y meditada del universo narrativo en cuanto a componentes, mecánicas, estética y posibilidades de participación y expansión del storyworld.

\section{Método: La retórica procedural}

Cuando Aarseth introduce el concepto de "ergódico" en la literatura sobre narrativa, da un paso adelante en la idea que contempla cómo el videojuego añade, para completar su lectura por parte del jugador, la necesidad de actuar en la diégesis, esta vez a través de las reglas que propone el propio juego. La literatura ergódica se define por el modo en el que el texto funciona y es leído: cómo el lector requiere un "esfuerzo relevante para atravesar el texto" (Aarseth,1997:1). Con esto no está hablando Aarseth de las dificultades de comprensión del texto, sea éste lineal o no lineal, sino de la nueva forma que desde el cibertexto el usuario accede a él: se trata de textos narrativos semejantes a laberintos, mundos en los que el usuario realiza una exploración intensa y se compromete con la narrativa misma no tanto con el significado del texto. El lector del cibertexto es literal y realmente un "jugador" y el texto, un "mundo-juego" o un "juego-mundo". Con la cibertextualidad se da paso a una forma narrativa con una complejidad diferente a la de las narrativas tradicionales en tanto que pone en jaque tres elementos: al texto - al operador - a la máquina. La intromisión de la máquina en el proceso no es la razón por la que el cibertexto requiera su propia etimología, es la interacción con el usuario lo que resemantiza el proceso.

Si se admite la posibilidad del videojuego como relato, con el desarrollo de convenciones narrativas específicas, dichas convenciones lo separan de la narrativa tradicional en el sentido que éstas incorporan la posibilidad de actuación como atributo de su especificidad. Dicha actuación en el universo narrativo permite que al jugador se le otorgue una manera de articular un papel esencial en lo que ocurre 
44| Mar Marcos Molano, Sergio Fabián Romero Chamorro y Michael Santorum González MONOGRÁFICO

en éste $\mathrm{y}$, a diferencia de los relatos clásicos, se le proporcionan también las herramientas para controlar lo que tendrá lugar en el espacio tiempo representado.

Si bien es cierto que un juego sólo se inicia cuando el jugador lo arranca y aún más, para que continúe necesita de su intervención, la actuación en el entorno de inmersión no es libre porque no deja de ser una ilusión más o menos pronunciada por la presencia dinámica en un mundo alternativo, pero ilusión a fin de cuentas. Lo que ocurre es que esa libertad parcial queda eclipsada por la posibilidad del "aquí" y "ahora" que permite la simulación del juego, aumentando la impresión de presencia y participación.

Avanzando en el desarrollo teórico y, desaparecido el interés por la polarización en el debate académico en torno al videojuego (Ryan, 2001; Darley, 2000; Jenkins, 2004 o Bogost, 2006), nuestra inquietud no es preguntarse si los videojuegos son juegos o son narraciones, sino en qué manera los juegos son narrativos: los videojuegos pueden suponer, y así lo creemos, una forma de experiencia narrativa en tanto que narrativizan la experiencia de juego. De esta manera se pretende explorar nuevas aproximaciones no estrictamente alineadas con las posturas clásicas que dividían el análisis del videojuego de manera innecesaria. Partimos de la necesidad de jugar para, a partir de la experiencia de juego, consumar el acto narrativo.

Sin embargo, Jenkins nos advierte sobre que "la experiencia de jugar no puede simplificarse en la experiencia de la historia" (Jenkins, 2004: 2). Participamos de esta idea, en tanto que consideramos que las historias ejercen de perímetro donde encajar las verdaderas relaciones estéticas del juego. Las historias del videojuego se desarrollan en el interior de una diégesis en la que se marcan límites temporales y espaciales según estrategias dramáticas. El autor construye el relato del videojuego a partir de unas mecánicas de juego y, por extensión, tiene el control del proceso narrativo en lo que se refiere al argumento aún teniendo en cuenta que en el videojuego no es el argumento el que determina el juego, dado que idénticas mecánicas se ajustan a argumentos dispares.

Retomando el concepto clásico de Chris Crawford sobre "proceduralidad" entendida como la capacidad de los ordenadores para ejecutar procedimientos en forma 
de reglas que, en un entorno inmersivo representen un mundo imaginario, Bogost (2006) define la "retórica procedural" como un diseño de reglas deducidas como estructuras lúdicas que determinan "qué se puede" y "qué no se puede hacer" en un entorno interactivo como el videojuego. El hecho de que sean unas reglas las que impidan hacer determinadas acciones provoca un vacío que el jugador suple como bien le parezca, es lo que Bogost ha denominado "entimema de procedimiento". La retórica del entimema resulta un interesante recurso para agilizar el relato y dotar de claridad expositiva el texto al presuponer el conocimiento de determinadas premisas o la capacidad del jugador para deducirlas, evitándose digresiones autorales innecesarias en la articulación de la narración. Visto así, Bogost podría entender el videojuego como una suma de "entimemas procedurales" que el jugador transita gracias a la interacción. De esta manera, puede entenderse que el videojuego establece una recepción particular y performativa, cuya autoría queda diluida entre el diseñador y el jugador. Un diseñador que propone reglas y un jugador que recorre trayectos narrativos a partir de las acciones que desarrolla: somos protagonistas de la acción simbólica independientemente del contenido. $Y$ es en este sentido que los videojuegos suponen una experiencia narrativa al narrativizar la experiencia de juego.

\subsection{Los componentes del Storyworld}

El concepto de "universo narrativo" ha germinado con fuerza no solo en la narratología sino en la cultura en general: existen representaciones multimodales de mundos narrativos que combinan varios tipos de signos, y también mundos narrativos transmediales que se implementan simultáneamente en diferentes plataformas. Por ello, si bien la narratología brinda una buena perspectiva de abordaje del concepto de "universo narrativo", se debe tener en cuenta que concebir el storyworld como una representación que trasciende a los medios, no solo amplía el alcance de la narratología más allá de su territorio "nativo" entendido como narrativa basada en el lenguaje - tanto porque el lenguaje fue uno de los primeros medios en el que se contaron las historias, como porque la narratología clásica se desarrolló principalmente pensando en la literatura de ficción-, sino que también proporciona un centro de convergencia muy necesario en los estudios de medios. "Any attempt to adequately discuss the manifestation of narrative meaning in 
46| Mar Marcos Molano, Sergio Fabián Romero Chamorro y Michael Santorum González MONOGRÁFICO

different media must begin with the assessment of the relations between narratological concepts and media categories" (Ryan \& Thon, 2014: 3-4).

El concepto storyworld puede inscribirse en una serie de términos utilizados por un amplio rango de investigadores del discurso -teóricos, críticos, narratólogos...-, donde aparecen expresiones como "realidad representada", "mundo ficcional" o "mundo del autor". Sin embargo, según Ryan \& Thon, storyworld no se corresponde completamente con ninguno de ellos. Afirman que, en referencia al concepto más afín de mundo ficcional, storyworld es más amplio porque cubre tanto las historias factuales como las de ficción, es decir, "las historias contadas como verdaderas del mundo real y las historias que crean su propio mundo imaginario, respectivamente" (Ryan \& Thon, 2014: 33-34).

En realidad, esta diferenciación entre historias factuales y ficcionales se complica, a la vez que se desdibuja, si se problematiza el status de factual y ficcional, haciendo hincapié en sus aspectos simbólicos. De alguna manera, al estar implicado un sujeto atravesado por el lenguaje, "toda historia siempre es ficcional" (Lacan, 1975: 36). Por otro lado, el uso de storyworld supone espacializar la narrativa a la vez que narrar el espacio, esto es, instituye una geografía del relato:

In 1997 (and again in 2011), Janet Murray identified spatiality as one of the four major distinctive properties of digital media, along with being procedural, participatory, and encyclopedic. This pronouncement, which falls in line with Fredric Jameson's (1991) claim that late twentieth-century culture is characterized by a "spatial turn," has been widely accepted by researchers (Ryan, 2016, posición en Kindle 2422-2426).

Siguiendo a David Herman, podemos concebir los storyworld como los "planos para un modo específico de creación del mundo" (Ryan \& Thon, 2014: 33) aunque en realidad, sería más pertinente decir para la "reinvención del mundo". La experiencia de lo narrado se da en la "fusión de horizontes" (Gadamer, 1996: 452 - 453) de lo propuesto por el autor y lo interpretado por el receptor. Ubicar la existencia del storyworld - y de la obra-, en la fusión de horizontes, es fundamental ya que lo despoja de toda connotación estática: "A storyworld is more than a static 
container for the objects mentioned in a story; it is a dynamic model of evolving situations, and its representation in the recipient's mind is a simulation of the changes that are caused by the events of the plot" (Ryan \& Thon, 2014: 33-34).

En el caso particular de las narrativas interactivas y transmediales, el receptor no solo interpreta sino que actúa y/o juega, por lo que, las características del storyworld como espacio-tiempo dinámico, abierto —o semi-abierto-, y recorrible, se acentúan. La ilación y generación de las tramas está íntimamente ligada a los trayectos posibles en el territorio narrativo realizado por el usuario en plataformas o medios semiabiertos - como las plataformas de video interactivo 0 los videojuegos - , o abiertas - como en el caso de experiencias transmediales "orgánicas" (Bernardo, 2014, posición en Kindle 276)—. Es en este último caso en donde el concepto de storyworld adquiere su máxima dimensión en tanto que podemos aplicar una perspectiva "lógica" en donde la trama es un constituyente más del storyworld, de tal manera que cualquier cambio significativo en ella, harán que el storyworld sea otro:

If a text rewrites an existing narrative, modifying the plot and ascribing different features or destinies to the characters, it creates a new storyworld that overlaps to some extent with the old one. While a given storyworld can be presented through several different texts, these texts must respect the facts of the original text if they are to share its logical storyworld (Ryan \& Thon, 2014: 5).

En el caso de una interacción cerrada, el lector, como un voyeur, recorre los trayectos preestablecidos no pudiendo actuar sobre ellos. Pero si aplicamos la concepción "imaginativa" descrita por Ryan, son los eventos los que componen el storyworld y no las tramas, las cuales son generadas o reinventadas por el usuario al realizar los propios trayectos narrativos. En estos casos, las tramas no son constituyentes del storyworld sino que se actualizan y desarrollan en la convergencia de las actuaciones del usuario con los elementos del universo narrativo, no sin tropiezos y fracasos, como suele ocurrir cuando se juega un videojuego. 


\section{Desarrollo: El papel del storyworld en el Juego Documental Interactivo}

Se comprueba cómo los videojuegos son una extraordinaria herramienta para la producción simbólica, una nueva manera de relacionarnos con el mundo y, por lo tanto, una poderosa máquina para la transformación política, social y cultural. También es el autor el que establece las reglas del juego que determina la relación del jugador con su personaje vicario y la posible transformación del personaje a través de la superación de niveles, pero en este punto el control es compartido con el jugador. Ahora bien, en la mayoría de los videojuegos, los enigmas son siempre similares y la resolución es más una cuestión técnica que argumental. Es por esta razón, que la clausura del relato, y con ella la actuación del jugador en el mismo, adquiere una dimensión de naturaleza más técnica que de conocimiento, reflexión o crítica: los finales no se basan en las vastas redes de complejas relaciones entre personajes, como en la ficción tradicional, sino que responden a preguntas de índole más práctico.

La actuación, hasta ahora desarrollada en el videojuego a partir de la construcción de entornos de inmersión más sofisticados gracias al perfeccionamiento de sus gráficos, ha conseguido intensificar la sensación de presencia en mundos más realistas a modo de simulacros simbólicos extasiados de mímesis, pero ha dejado en segundo término la construcción de significaciones. El interés del videojuego no puede ser mostrar la fotografía estática y monofocal de los mundos que representa, sino diseñar un storyworld creíble para el desarrollo de una estrategia narrativa al servicio del juego y el jugador. Los mundos dejarían de ser lugares para pasar a ser verdaderos universos narrativos que contribuyeran a la identificación del jugador: Al transformarlo en un espacio tridimensional que se experimenta a través del movimiento y de las acciones de unos personajes que lo navegan, puede entenderse cómo el videojuego construye la conciencia espacial y cómo el espacio se transforma en elemento significativo para el juego.

En este sentido, la riqueza y complejidad de la narración caleidoscópica es extraordinaria y puede aprovecharse para construir una realidad simbólica, observable desde distintos puntos de vista y de la que poder participar: desarrollar 
tramas a partir de los trayectos, experimentar las sensaciones, posicionarnos con diferentes puntos de vista gracias a la posibilidad dramática de cada uno de los personajes... Una construcción de mundos virtuales que no se limite ya a mero diseño de niveles o de experiencias de repertorio, sino que atienda a las posibilidades críticas y emancipadoras de posibles modos de habitar espacios, ello se establece como la posibilidad de resistir a un Sistema que quiere, siempre, cerrarse en la pura inmanencia de lo que "es así porque es así" (Siabra, 2015: 51).

Es posible hablar en este punto de un espacio que se reinventa utilizando la herencia de representaciones narrativas anteriores. Un espacio dramático que supera la propuesta estímulo-respuesta del juego en el que frente al espacio plano, entendido como lugar para el desarrollo de acciones sucesivas, se eleve el espacio poliédrico de lo simultáneo, que construya auténtica conciencia espacial, proceda a la espacialización psicológica del drama y se transforme finalmente en elemento significativo de un nuevo lenguaje. De esa manera podríamos acceder a una narrativa caleidoscópica que podría asentarse en la búsqueda de unas historias a través de unos espacios y de unos sujetos que los habiten. Al actuar en dichos espacios, los lugares, sujetos y objetos que lo configuran lo transformarán en espacios de representación dramática poblada de interacciones. Éste resultará el lugar ideal donde hacer germinar una suerte de placer estético, que conduzca a la complejidad de las relaciones simbólicas, dentro de un tejido estructural que abandone el reduccionismo tecnológico y se vea influido realmente, y en este sentido, de las narrativas tradicionales, pobladas de seres complejos en permanente estado de transformación.

\subsection{Hacia una narrativa emergente y caleidoscópica}

El videojuego permite a sus jugadores transitar el terreno de lo simbólico: el mundo físico nos permite construir el mundo simbólico y a su vez, el mundo simbólico nos permite entender el mundo físico y las relaciones que establecemos con él. Si lo simbólico se construye sobre las ruinas simbólicas precedentes procediendo a su deconstrucción para construir nuevas significaciones (Cabañes, 2012), nada impide que busquemos, para la construcción simbólica del videojuego, piezas que encajen provenientes de otras formas narrativas anteriores, solicitando a su expe- 
riencia y desarrollo la búsqueda de respuestas, aunque topemos con la dificultad de que habitamos un espacio simbólico lleno de significaciones preestablecidas.

El desarrollo tecnológico ha permitido la complejidad gráfica y el desarrollo de una narración donde argumento y jugabilidad se "embeben" en un texto que conserva los modos de producción clásicos heredados del cine o la literatura, ahora bien, sin tener en cuenta que el videojuego se despega de la narración aristotélica y que el argumento debería formar parte de la jugabilidad y no ser una adenda de ella.

Pese a los intentos de hibridación, actualmente la "narrativa embebida del videojuego es completamente accidental y accesoria, ya que éste cuenta con otro tipo de narrativa que le es inherente" (Monchan, 2015: 55), la que hemos denominado narrativa emergente, entendida como aquella que emerge no de historias sin autoría precisa, sino de interacciones entre los jugadores y los procedimientos que rigen la jugabilidad y que manifiesta la relación entre los objetivos propuestos por las mecánicas y las motivaciones de la narrativa:

El juego emergente es una tendencia (...) donde los mundos de juego resultan sumamente creíbles y permiten que el juego se desarrolle a modo de simulación simplificada de la realidad. La historia está integrada dentro de ese mundo gracias a una serie de objetivos que el jugador debe cumplir para poder seguir avanzando en la historia, aunque lo verdaderamente novedoso es la vivacidad y autonomía del entorno y su influencia decisiva en la experiencia del juego, ya que el jugador debe estar atento a los cambios que se producen del entorno (Santorum \& Peinado, 2004: 2)

Aparecen así tres elementos esenciales para provocar el tránsito entre modos de contar: desde el desarrollo de la Inteligencia Artificial — como automatismos capaces de gestionar la experiencia interactiva de juego-, a la personalización de contenidos - con el fin conseguir experiencias de juego distintas en función del jugador-, hasta la integración entre el contenido del autor y el juego emergente para generar comportamientos inesperados. 
La emergencia permite superar el hermetismo narrativo del videojuego al dar un paso adelante respecto de los procesos narrativos de otros medios y favorecer lo que consideramos le es específico: para provocar una experiencia de juego, el diseño narrativo tiene que exceder las convenciones tradicionales de representación y añadir una integración entre el diseño del juego y el contenido narrativo, esto es, considerar de manera indispensable y prioritaria las decisiones tomadas por los jugadores en el entorno propuesto por las mecánicas de juego. Todas estas necesidades confluyen en la concepción del storyworld.

\subsection{El caso de Fort McMoney}

Puede afirmarse que los juegos documentales interactivos provienen de la hibridación de dos campos de desarrollo de contenido muy disímiles tanto en su historicidad como en sus modos de producción: por un lado, por la influencia de la tradición del documental cinematográfico, que lo sitúa en el ámbito del audiovisual $\mathrm{y}$, por otro, por la reivindicación de lo interactivo como elemento nuclear, que lo sitúa en el ámbito de la producción informática:

Initially, the web was composed solely of simple HTML pages (text-only), but in 1993, the «IMG» tag was invented, which opened up the possibility of inserting images. In the same year, forms were created, making user interaction a possibility. In 1994, with the advent of Netscape Navigator, the dominant browser in the mid-1990s, new elements of presentation were created (alignment, text attributes, flashing ...). From then on, the main goal of engineers was to improve the visual aspect of web pages to increase the impact of information on users. (...) The internet had become fully interactive. (...) Using web tools (multimedia, interactivity), the producers will attempt to give a playful character to the information that they are conveying. Many of these techniques have been inspired by creators of educational PC and video games. The idea is, while taking into account any technical, economic or time constraints, to imagine different narrative styles capable of providing the player with the pleasure they seek in games: the feeling of power, exploration and discovery, emotional involvement... Different narrative elements are then introduced to ensure the success of the games: for example the concept of the avatar (the player is a 
$52 \mid$ Mar Marcos Molano, Sergio Fabián Romero Chamorro y Michael Santorum González MONOGRÁFICO

character), and levels of network games. Now that we have internet connection speeds sufficient to adapt these technologies to the Web, the webdocumentary has emerged (Villers \& Sarini en Lietaert, 2011, posición en Kindle 365)

Actualmente, y de acuerdo con Aston, Gaudenzi \& Rose la denominación I-Docs abarca proyectos que pueden encontrarse descritos como:

(...) web-docs, transmedia documentaries, serious games, locative docs, interactive community media, docu-games and now, also, forms including virtual reality non-fiction, ambient literature and live performance documentary. We do not focus only on visual screen practices as i-docs can include work where audio leads, or where immersive and mixed reality projects use actuality and reportage, aural history and poetry, all opening up new terrains for documenting away from the lineage of documentary film (Aston, Gaudenzi \& Rose, 2017, posición en Kindle 298)

En este marco conceptual, "Fort McMoney" (Dufresne, 2013) se posiciona como un juego de estrategia con aspecto de documental interactivo en modo conversacional para web sobre Fort McMurray, población situada en Alberta, Canada. El documental utiliza elementos propios de los juegos para permitir a los jugadores decidir sobre el futuro de la ciudad e intentar desarrollar de forma responsable la explotación de Athabasca, las reservas de arenas petrolíferas (o bituminosas) más grandes del mundo. Esta exploración petrolera implica problemas ambientales, sociales y económicos que "Fort McMoney" saca a la luz y trata de asegurar al jugador un rol activo en la búsqueda de una solución: "Fort McMoney" presents a very complex structure, since it offers audiences several narrative possibilities, as well as the opportunity to navigate backwards and forwards through the documentary's contents." (Nogueira, 2015: 81).

Para su realización, David Dufresne junto a un equipo del National Film Board de Canadá en coproducción con Toxa y el canal ARTE de Francia, grabó 2.000 horas de material en 22 locaciones de Fort McMurray, que incluyeron 55 entrevistas con ciudadanos, desde homeless al Ministro de Ambiente de Canadá o el presidente del gigante de la energía Total. 
Los jugadores pueden recorrer virtualmente la ciudad, encontrarse con residentes y requerir su opinión sobre determinados aspectos (Figura 1). Está estratificado en niveles, y tiene una estructura progresiva, según la cual los usuarios deben completar un conjunto de tareas para obtener acceso a ciertas áreas. La opción elegida por el espectador tiene un impacto en la vida de la ciudad, ya que va acompañada de una acumulación de puntos que, mediante su conversión en votos, le permite votar en el referéndum virtual de la ciudad que ejerce influencia, junto con otras opciones de usuario. Más específicamente, cada acción realizada por los usuarios les otorga puntos de influencia que les permiten votar en referendos y por lo tanto contribuir, como parte de una experiencia colectiva con otros usuarios, a la transformación de Fort McMoney/Murray.

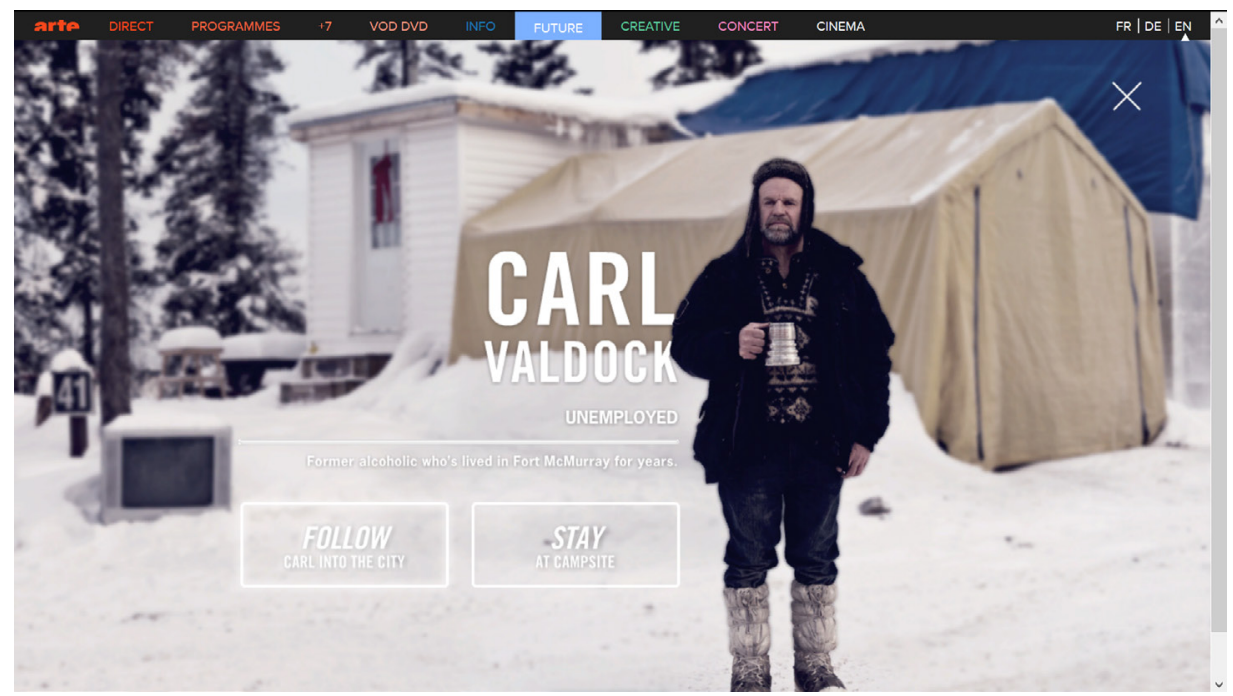

Figura 1: Personaje del juego.

Fuente: captura de juego Fort McMoney, web PC.

"Fort McMoney" es un híbrido que combina representación audiovisual, jugabilidad y simulación con chat en tiempo real. Integra el rol tradicional "informacional" del documental con una plataforma deliberativa por chat que apunta a la formación de una esfera pública como un espacio democrático, inclusivo, informado y participativo (Figura 2). 


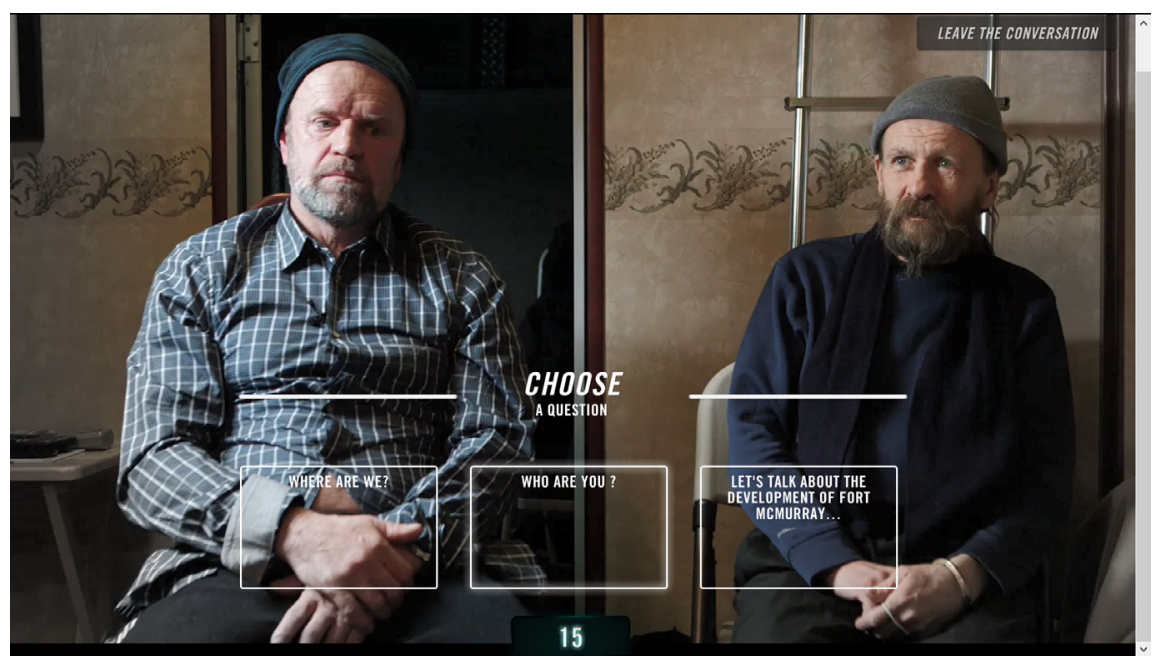

Figura 2: sistema de conversación.

Fuente: captura de juego Fort McMoney, web PC.

Para su diseño, Dufresne señala que el contenido de investigación del documental (entrevistas y secuencias de video) tiene como objetivo representar los problemas de manera objetiva, pero son el juego y la simulación los que presentan oportunidades para fomentar un modo diferente de participación. El juego en particular se ve como una forma de promover una relación más personal con los problemas: “Los espectadores se convierten realmente en actores, forjando su opinión, evaluando sus pensamientos y expresando sus emociones y subjetividad en el corazón del programa. "Fort McMoney" no quiere moralizar, son los propios jugadores quienes, a través de sus acciones, desarrollan su sentido crítico “. (Dufresne citado por Aston, Gaudenzi \& Rose, 2017, posición en Kindle 477)

\section{3. "Fort McMoney" como storyworld}

Al realizar una articulación entre lo aportado desde la noción de storyworld a la descripción, prescripción y operación del proyecto "Fort McMoney", con lo propuesto desde la perspectivas de las narrativas ergódicas y las narraciones emergentes y caleidoscópicas aportadas por la jugabilidad, y aún más, si lo comparamos con su caracterización como interactividad en modo conversacional que remite a las características enunciadas por Andrew Lippmann (en Gifreu, 2013: 91) de “interrupti- 
bility", "graceful degradation", “limited look-ahead", "no default", e "impressión", el juego Fort McMoney" puede causar la percepción en el usuario de que las posibilidades de su mundo se extienden al infinito: "interruptibility": la acción puede ser interrumpida en cualquier momento por el usuario; "graceful degradation": una pregunta no contestada puede llevar hacia una transición suave; "limited look-ahead": la plataforma debe responder en tiempo real a las órdenes del usuario; "no default",: la conversación debe ser impredecible y no basada en frases hechas y "impression of infinite database", la interacción debe parecer eterna.

En cuanto a la interfaz, los jugadores se enfrentan en cada episodio con una serie de personajes y objetos diseminados en un amplio campo visual recorrible. Pueden avanzar en la historia y construir su propia narrativa a través de esos "signos interactivos" que pueden ser manipulados directamente. En general, estos signos cambian transitoriamente de apariencia y se convierten en otros signos, es decir, cada vez que el espectador hace clic en un botón -incluso si no tiene la apariencia de un botón sino de personaje o de objeto-, algo sucede para mostrarles que su decisión está en curso. Este comportamiento es crítico al proporcionar retroalimentación sobre la acción del usuario mientras se lleva a cabo.

Por último, al analizar la estructura de navegación de "Fort McMoney", encontramos una combinación compleja de nodos y conexiones destinadas a posibilitar una gran cantidad de trayectos. El diagrama resultante puede categorizarse como un modelo no lineal en red según Martinec \& Van Leeuwen (en Nogueira, 2015: 84), que consiste en un conjunto no jerárquico ni centralizado de información, mayormente contenida por segmentos documentales. Esta intención deliberada de no tener un arco dramático, sino de proponen al usuario la posibilidad de exploración con gran flexibilidad, lo acerca al ideal de la narrativa caleidoscópica y emergente, ayudando a crear esa percepción de infinitud de la red a explorar.

\section{Conclusiones}

1. El juego documental interactivo resulta un formato adecuado para desarrollar experiencias narrativas de no-ficción en la tradición documental, aunque es crucial para lograr el efecto en el usuario, el equilibrio en la 
utilización de estrategias de producción ficcionales y no ficcionales. Los diseñadores y arquitectos de historias deben entender que son los personajes $\mathrm{y}$ los escenarios quienes aportan un plus a la verdad mediante una mimesis cuidada y creativa de la realidad, pero, siempre teniendo en cuenta que la fidelidad y los efectos de verdad de los eventos y las tramas, se logran con procedimientos más próximos a la ficción.

"Fort McMoney", como uno de los mayores exponentes del género, nos permite visualizar las fortalezas y debilidades de un desarrollo de estas características. El enfoque documental es muy valioso a la hora de realizar las entrevistas, por ejemplo, pero se vuelve una debilidad al cerrar demasiado las posibilidades de interacción verbal con los personajes. Un ejemplo son los diálogos que el usuario puede sostener con la alcaldesa del pueblo, que resultan limitados y elípticos. Quizá sea ese apego a la verdad, muy propio de cierta concepción de lo documental, el que conspire en contra del efecto a lograr por la propuesta. En nuestra opinión y entendiendo, como ya lo hemos afirmado antes, que la ficción es la mayoría de las veces más efectiva para la transmisión del efecto de verdad que la intención de la correspondencia término a término del discurso con el referente, los personajes deberían poder tener un repertorio de respuestas y cuestiones actuadas, pero que extiendan la posibilidad de interacción dialógica del jugador con ellos y así lograr un efecto de verdad mayor.

2. Transitar el mundo a través de la construcción de "mundos simbólicos" es una posibilidad del videojuego. Esos mundos simbólicos no pueden conformarse con adoptar los procesos de construcción clásica convenientes a otros relatos. El videojuego, instalado en la cultura de la posmodernidad, ha nacido en el seno del relato no lineal y por lo tanto, el paradigma de su construcción narrativa se despega necesariamente del modelo aristotélico. La narración "ergódica" que propone el storyworld, establece un universo en el que el sujeto es el centro no ya del enunciado sino de todo el proceso enunciador a través del espacio simbólico. 
En "Fort McMoney", podemos detectar la posición activa por parte del usuario, aunque la mecánica de juego sea un tanto simple y repetitiva, desprovista de hooks que nos lleven a querer seguir jugando. El diseño general es centrado en el usuario, lo que constituye una gran ventaja, aunque esa preeminencia tiende a perderse cuando debemos realizar trayectos conversacionales con otros personajes. Esto nos lleva otra vez a la suma importancia que tiene el diseño del storyworld a la hora de producir una experiencia de narrativa interactiva jugable: elegir y setear los ambientes y paisajes, definir personajes cada vez más complejos pero, también seleccionar eventos y eventos mentales que permitan el desarrollo de trayectos ricos variados e inesperados que sostengan el interés e integren a la mecánica de juego - primer nivel de la narrativa - las narrativas emergentes producto de la co-autoría del diseñador y el jugador.

3. La construcción de niveles y/o experiencias de repertorio no deja de ser la construcción de un texto lineal, ése precisamente del que huye la posmodernidad y, por extensión, debería huir el videojuego. La compleja dinámica narrativa del videojuego será sólo potencialidad mientras al jugador no se le ofrezcan espacios multifocales de relaciones complejas no sólo entre personajes, sino entre éstos y el propio jugador, sustancias narrativas que provoquen lecturas complejas a través de sus acciones y las repercusiones de éstas, y no saltos de un punto de información a otro. En este sentido "Fort McMoney" da un paso adelante en tanto que se erige como un mundo virtual, un storyworld complejo con gran cantidad de lugares y personajes con los que establecer interacciones para concebir historias posibles. ¿Es este mundo una ficción?; ¿Son éstos personajes ficticios?..., el juego conversa con la realidad a través de la construcción de un avatar autorreferencial que crea nuestra autoimagen en un juego donde se nos pide que elijamos si la ciudad debe seguir produciendo petróleo o cerrar la industria. Así, el juego documental interactivo debería revisar su propia ontología $\mathrm{y}$, siendo consciente de las necesidades que cubre en el contexto de lo posmoderno, ser capaz de crear nuevas experiencias narrativas para la producción de subjetividad. 
58| Mar Marcos Molano, Sergio Fabián Romero Chamorro y Michael Santorum González

\section{Referencias}

Aarseth, E. (1997). Cybertext: perspectives on ergodic literature. Baltimore: John Hopkins University Press.

Aston, J., Gaudenzi, S. \& Rose, M. (Eds.). (2017). i-Docs. The evolving practices of interactive documentary. London \& New York: Wallflower Press.

Bernardo, N. (2014). Transmedia 2.0: How to create an entertainment brand using a transmedial approach to storytelling. Lisboa: BeActive Books, Kindle edition.

Bogost, I. (2006). Persuasive Games. Cambridge: Londres MIT Press.

Cabañes, E. (2012). Del juego simbólico al videojuego: la evolución de los espacio de producción simbólica, Videojuegos y juventud, INJUVE, Revista de Estudios de Juventud, septiembre 2012

Darley, A. (2000). Cultura visual digital. Espectáculo y nuevos géneros en los medios de comunicación. Barcelona: Paidós.

Dufresne, D. (Director). (2017, octubre 31). "Fort McMoney". [webdocumentary]. Canada-France: NFB, ARTE \& TOXA. Recuperado de http://fortmcmoney.com

Gadamer, H. (1996). Verdad y método. Fundamentos de una hermenéutica filosófica. Salamanca: Sígueme Ediciones.

Gifreu, A. (2013). El documental interactivo, Barcelona: UOCPress.

Jenkins, H. (2004). Game design as Narrative Architecture (CL). Cambridge: Londres MIT Press.

Lacan, J. (1975). Entrevista en la Universidad de Yale. Scilicet, (6/7).

Lietaert, M. (Ed.) (2011). Webdocs. A survival guide for online filmakers. Brussels: Not so crazy! Productions, Kindle edition.

Martinec, R. \& Van Leeuwen T. (2009). The lenguage of new media design: Theory and practice. London: Routledge.

Monchan, J. (2015). A mí no me pagan por escribir: hacia una definición del diseño narrativo videolúdico. Bit y Aparte, Revista interdisciplinar de estudios videolúdicos. Enero 2015.

Nogueira, P. (2015). Ways of feeling: audience's meaning making in interactive documentary through an analysis of "Fort McMoney". Punctum, 1(1).

Peinado, F. \& Santorum, M. (2004). Juego Emergente: ¿Nuevas formas de contar historias en videojuegos? Icono14, Revista de comunicación y tecnologías emergentes. 
Ryan, M. (2001). La narración como realidad virtual. La inmersión y la interactividad en la literatura y los medios electrónicos. Barcelona: Paidós.

Ryan, M. (2016). Narrating Space / Spatializing Narrative: Where narrative theory and geography meet. Ohio State: University press, Kindle edition.

Siabra Fraile, J. A. (2015). Gesto, Alienación y Videojuego. Bit y Aparte, Revista interdisciplinar de estudios videolúdicos. Julio 2015.

Žižek, S. (1999). El acoso de las fantasías. México: Siglo XXI Editores

\section{(c) $)(i)$}

Esta obra está bajo una licencia de Creative Commons Reconocimiento-NoComercial 4.0 Internacional. 